\title{
$\underline{\mathbf{P}-157}$
}

\section{Design, Synthesis and Biological Evaluation of Diarylpentanoid Derivatives as New Anti-Inflammation Agents}

\author{
Siti Munirah Mohd Faudzi ${ }^{\mathrm{a}}$, Faridah Abas ${ }^{\mathrm{a}, \mathrm{b},{ }^{*}, \text { Khozirah Shaari }^{\mathrm{a}, \mathrm{c}} \text {, Intan Safinar Ismail }}{ }^{\mathrm{a}, \mathrm{c}}$, Syahida \\ Ahmad $^{\text {d }}$, Kok Wai Lam ${ }^{\text {e }}$, Chau Ling Tham ${ }^{\text {, }}$, Daud Ahmad Israf ${ }^{f}$, Nordin Hj Lajis ${ }^{\mathrm{g}}$ \\ ${ }^{a}$ Laboratory of Natural Products, Institute of Biosciences, Universiti Putra Malaysia, 43400 UPM Serdang, Selangor, \\ Malaysia; ${ }^{b}$ Department of Food Science, Faculty of Food Science and Technology, Universiti Putra Malaysia, 43400 UPM \\ Serdang, Selangor, Malaysia; ${ }^{c}$ Department of Chemistry, Faculty of Sciences, Universiti Putra Malaysia, 43400 UPM \\ Serdang, Selangor, Malaysia; ${ }^{d}$ Department of Biochemistry, Faculty of Biotechnology and Biomolecular Sciences, \\ Universiti Putra Malaysia, 43400 UPM, Serdang, Selangor, Malaysia; ${ }^{e}$ Drug and Herbal Research Center, Faculty of \\ Pharmacy, UniversitiKebangsaan Malaysia, 50300 Kuala Lumpur, Malaysia; ${ }^{f}$ Department of Biomedical Science, Faculty \\ of Medicine and Health Sciences, Universiti Putra Malaysia, 43400 Serdang, Selangor, Malaysia; ${ }^{g}$ Scientific Chairs Unit, \\ Taibah University, P.O. Box 30001, Madinah al Munawarah, 41311 Saudi Arabia; E-mail: faridah@food.upm.edu.my
}

Curcuminoids has been reported to possess a variety of biological and pharmacological applications, but its efficacy has been limited by its poor bioavailability and unstable structure. In this study, 52 curcumin related diarylpentanoid analogues were designed and synthesized, and their pre-screening inhibition against nitric oxide (NO) suppression in interferon-gamma (IFN$\gamma$ )/ lipopolisaccharide (LPS)- activated RAW 264.7 cells was evaluated. The structures of this new series of diarylpentanoids, consisting of mono-carbonyl and two consecutive methylene moieties in the middle linker, were established using ${ }^{1} \mathrm{H}$ and ${ }^{13} \mathrm{C}$ NMR spectrometry and mass spectral analyses. Most of the compounds showed good activity with more than $50 \%$ inhibition. The present result might contribute to the development of improved anti-inflammation agents. 